\title{
Predictors of Depressive Symptoms: What Are the Roles of Geography and Informal Social Support?
}

\author{
Timothy S. Killian, Megan Penfield \\ Department of Human Environmental Sciences, University of Arkansas, Fayetteville, USA \\ Email: tkillian@uark.edu
}

Received August 23 ${ }^{\text {rd }}, 2012$; revised September $25^{\text {th }}, 2012$; accepted October $9^{\text {th }}, 2012$

\begin{abstract}
Using data from the 2004 wave of the Health and Retirement Study (HRS), three central research questions were examined. First, are there variations in depressive symptoms by geographic region? Second, are variations in depressive symptoms related to informal social support? Third, are there interactions between geography and informal social support in regard to predicting depressive symptoms? Results from this study found a small, but significant difference in depressive symptoms by geography region. Also, informal social support from children and friends were predictive of lower levels of depression. Furthermore, informal social support interacted with region to explain additional variation in depressive symptoms. Participants' perceptions that they could rely on their adult children to meet their needs was more salient in regard to reducing depressive symptoms for exurban than non-exurban participants, and increased limitations in mobility, strength, and fine motor skills were more influential in explaining depressive symptoms in exurban than other persons.
\end{abstract}

Keywords: Depression; Aging; Rurality; Social Support; Older Adults

\section{Predictors of Depressive Symptoms: What Are the Roles of Geography and Informal Social Support?}

There are many social and personal costs associated with depressive symptoms in late life. In terms of social costs, older persons' depressive symptoms are positively related to the utilization of both formal and informal caregiving. It has been estimated that the caregiving costs associated with depressive symptoms in older persons in the US are about $\$ 9$ billion per year (Langa, Valenstein, Fendrick, Kabeto, \& Vijan, 2004). Callahan, Kesterson, and Tierney (1997) found that, when controlling for physical health, older persons who report a larger number of depressive symptoms are more likely to use emergency departments and be hospitalized, as well as incur greater diagnostic test charges over a one year period. Ambulatory costs and inpatient hospital costs have been estimated to be between 43 percent to 51 percent higher and 47 percent to 53 percent higher for depressed than for nondepressed older persons (after adjusting for chronic medical illness) (Katon, Lin, Russo, \& Unutzer, 2003). The same study found that increased medical costs were not significantly different between those actually diagnosed with depression and those reporting high depressive symptomatology; in either case, medical costs were significantly higher than those exhibiting less symptoms of depression.

In addition to the social costs associated with depressive symptoms, there are many personal costs. Older persons who report a greater number of depressive symptoms experience physical decline at faster rates than those who report lesser symptoms of depression, even after adjusting for health status and other sociodemographic factors (Penninx et al., 1998). Additionally, research has found that depression, along with poor social integration and dementia, are the most consistent predictors of death in older persons, especially for those over
75 years of age (Endegal, 1996). There are significant personal costs to family members that provide care for older persons reporting symptoms of depression. For instance, even after controlling for sociodemographic factors, disease, and disease symptoms, caregivers of older persons reporting greater symptoms of depression experience more strain and stress due to caregiving, which has been related to increased caregiver mortality (Schulz \& Beach, 1999).

There is increasing evidence that place of residence make one more likely to experience depressive symptoms and less able to cope with depression. Rathbone-McCuan and Bane (2003) indicated that limited mental health resources, geographic distance to services, attitudes toward areas. Furthermore, older rural persons might be more reluctant to use mental health services even when they are available because utilization of those services is perceived to be at odds with individualism and self-reliance that are especially valued in rural areas (Gatz $\&$ Smyer, 1992). For these reasons, in addition to the more rapid pace of population aging in rural areas (Rogers, 2002a), it is critical to understand variation in depressive symptoms across place of residence.

The purpose of this paper was to address the following questions. First, are there variations in depressive symptoms across place of residence? Second, are there variations in the provision of informal social support across place of residence? Finally, does informal social support mitigate depressive symptoms and, if so, does mitigation of informal social support vary by residence? Then, predictive models of depressive symptoms were developed that focused on variations in both residence and informal social support while controlling for physical health and sociodemographic variables likely related to depressive symptoms. mental health problems, the fear of stigmatization, and lack of affordable care were all barriers to mental health service utilization in rural. 


\section{Literature Review and Background}

The Center for Epidemiologic Studies Depression Scale (CES-D) (Radloff, 1977) is a widely-used measure of depression with well-established reliability and validity estimates when used with older adults (Himmelfarb \& Murrell, 1983; Kohout, Berkman, Evans, \& Cornoni-Huntley, 1993). Recent research on depressive symptoms using the CES-D has shown that depressive symptoms significantly affect quality of life in older persons. In a study of persons aged 71 years old and older, Penninx et al. (1998) found that depressive symptoms predicted declines in physical functioning across a span of four years, even after adjusting for baseline functioning scores, health scores, and sociodemographic variables. Also, using the CES-D, Wilson, Mendes de Leon, Bennett, Bienias, and Evans (2004) found a significant positive relationship between initial levels of depressive symptoms and cognitive decline during a fiveyear-period. Because of the social and personal costs associated with depressive symptoms among older adults, it is important to develop a greater understanding of variations in the experience of depressive symptoms that include variations in the context within which they are experienced and coped with.

Impairments in functioning and poor self-reported health have been frequently studied in association with depressive symptoms (e.g., Killian, Turner, \& Cain, 2005). It is clear that a limited ability to perform Activities of Daily Living (ADLs) and Instrumental Activities of Daily Living (IADLs) increases the likelihood of depression (Probst et al., 2006; Yang \& George, 2005). A recent study on over 22,000 individuals from 11 different European countries (Braam et al., 2005) found a positive relationship between physical health and depression in each country, although the magnitude of the relationship differed across countries. In particular, the association between physical health and depressive symptoms was more pronounced in the UK and Ireland than in western continental European and Scandinavian countries. Braam and colleagues hypothesized that this might be due to greater access to health services in western continental European and Scandinavian countries as compared to the western isles (UK and Ireland). Analogously, given the increased barriers in accessing health care services for rural US populations relative to persons living in more urban regions (Rogers, 2002b), it would be reasonable to expect that the association between physical health and depression would be greater in rural populations than nonrural. Poor self-rated health has been found to be a robust predictor of depression in older adults (Killian, Turner, \& Cain, 2005), with reported odds ratios as high as 5.6 for older individuals and 6.8 among the oldest old (those over 85 years old) (Djernes, 2006).

Beyond physical health, gender and marital status are also important predictors of depressive symptoms in older persons. In a review of literature on depression in older adults, Djernes (2006) found that older women were significantly more likely to have depressive symptoms and disorders than older men (with odds ratios as high as 3.4). However, other studies have suggested that this gender gap is reduced with aging (Ried \& Planas, 2002). Being married is associated with less depressive symptoms (Zunzunegui, Beland, Llacer, \& Leon, 1998). Bierman, Fazio, and Milkie (2006) suggested that married individuals report less depression than nonmarried individuals because of their greater access to socioeconomic and psychosocial resources. Additionally, research has shown that the transition to widowhood, especially when recent, doubles the likelihood that a person will be depressed (Djernes, 2006).

In their review of the literature on social relationships and health, House, Landis, and Umberson (1988) highlighted research which indicated that less socially integrated individuals suffer more physical and mental health problems and are more likely to die. In a study examining the relations between functional disability, depression, and perceived social support, Yang (2006) found that functional disability alone does not necessarily lead to increased depressive symptoms. Rather, it seems that functional disability, in conjunction with deficits in high-quality social relationships, contributed to higher levels of depresssion. Yang contended that improving the quality of social relationships in the elderly is a critical component to reducing risks of depression in older disabled persons. There is reason to believe that this might be especially true for rural older persons who often face significant barriers in accessing formal support (Rogers, 2002b) potentially making informal support more important for them than their nonrural counterparts.

Often left out of predictive models of depressive symptoms among older persons is geographic region. This is likely a key variable in understanding depressive symptoms for several reasons. First, as already noted, there may be more significant barriers to accessing rural mental health services in rural areas as compared to less rural areas (Rathbone, McCuan, \& Bane, 2003). Also, in spite of strong normative obligations of family members to provide assistance to aging family members (Killian \& Ganong, 2002), out migration of adult children may reduce the availability of informal caregiving assistance more for rural than nonrural aging persons (Johnson, 1998). Whereas technical interventions have demonstrated some success for improving the physical health of older persons living in rural areas (Buckwalter, Davis, Wakefield, Kienzle, \& Murray, 2002), there is only preliminary evidence for the effectiveness of telehealth strategies for improving psychological well being (Montani et al., 1997; Sumner, 2001). The purpose of this study, therefore, was to examine variations in depressive symptoms and informal social support across geographic region and develop predictive models of depressive symptoms with region as a predictor of depression.

\section{Methods}

\section{Sample}

Participants in this study were drawn from the 2004 wave of the Health and Retirement Study (HRS). HRS data were first collected in 1992 from persons born between the years 1931 and 1941, and have been collected biannually since then. Additionally, since 1998, data from three additional cohorts were also added: Aging and Health Dynamics (born prior to 1923), Children of the Depression (1923-1930), and War Babies (1942-1947). For the purposes of this study, we were interested in individuals at least 65 years old in 2004, and therefore persons from the War Babies cohort were not included. However, older persons from all other cohorts participated.

We chose to only include data collected in 2004 because it was in this wave of data collection that a so-called leave-behind questionnaire was piloted with 4000 participants. This leavebehind lifestyle questionnaire focused on psychosocial variables that dealt with attitudes towards life, family, friends, and work. Overall, 76.8 percent of those selected to complete the survey returned the questionnaire (Clarke, Fisher, House, Smith, $\&$ Weir, 2007). In our analyses, only those respondents that 
were selected to fill-out the psychosocial questionnaire, completed the questionnaire, and were at least 65 years old were included. As a result, our analyses were based on data collected from 1250 individual participants. Additionally, we also corrected our estimates using a specific weight that was developed by the HRS to adjust for selection and non-response to the questionnaire because it was not administered to all participants.

As can be seen in Table 1, the mean age of participants was about 73 years old, of which about 42 percent were male. Most of the participants were White, and while most were married, about 23 percent were widowed and 9 percent were unmarried. The average number of children of participants was about 3.4. Most participants were retired, although roughly 22 percent were still working.

\section{Measures}

Depression. In order to assess depressive symptoms, we used an abbreviated form of the CES-D available in the HRS. The CES-D is a widely-used measure of depression that has demonstrated high internal consistency and adequate discriminant validity (Radloff, 1977). Research has indicated that both long and short versions of the CES-D are reliable for usage in older populations (Himmelfarb \& Murrell, 1983; Kohout et al., 1993). Due to interview time constraints, the HRS employed a shortened version of the CES-D that consisted of 8-items. Specifically, participants were asked whether or not they had experienced 8 different indicators of depression over the past week (coded so $1=$ yes; $0=n o$ ). These were summed and the result was a single estimate of the number of depressive symptoms participants had experienced in the previous week. Total scores could range from $0-8$ with higher scores indicating more symptoms of depression. In a report on affective functioning measures in the HRS, Steffick (2000) indicated that the 8-item version of the CES-D has acceptable estimates of reliability (Cronbach's $\alpha$ s ranging from .78 - .81). Additionally, construct validity was established by comparing the shortened version of the CES-D to self-rated emotional health as well as examining expected relations between the CES-D and known predictors of depression. From these findings, Steffick concluded that the CES-D is an acceptable measure of depressive symptoms. In addition, this shortened version was acceptable for this study because we were attempting to examine variation in depressive symptoms, and not differentiating between those who were clinically depressed or not.

Rurality. In this study, rural status was assigned on the basis of the 10 category Beale Rural-Urban Continuum codes (Butler \& Beale, 1994) as provided by HRS. These codes are assigned based on participants' counties of residence at the time that they participated in the study. HRS collapses the scale into three variables exurban (codes 3 -9), suburban (codes 1 and 2), and urban (code 0). It should be noted that the label exurban used by HRS reflects the collapsing of the codes in a way that does not fully correspond to traditional definitions of rurality. However, given the limitations of the data set, it is the best approximation of rurality available in the non-restricted data. Moreover, in this study, the scale was further collapsed so that rural corresponded to Beale codes 3 - 9 and nonrural represented codes 0 - 2 .

Informal social support. The operationalization of informal social support was based on several questions about relationships with friends, family, and children. In terms of examining
Table 1.

Weighted means and standard errors of variables by rural status $(\mathrm{N}=$ 1250).

\begin{tabular}{|c|c|c|c|c|c|c|}
\hline \multirow[b]{3}{*}{ Variable } & \multicolumn{2}{|c|}{ Rural } & \multicolumn{2}{|c|}{ Nonrural } & \multicolumn{2}{|c|}{ Full sample } \\
\hline & $(\mathrm{N}=4$ & & $(\mathrm{N}=$ & 791) & $(\mathrm{N}=$ & 250) \\
\hline & $M$ & $S E$ & $M$ & $S E$ & $M$ & $S E$ \\
\hline CES-D $^{1}$ & $1.37^{*}$ & .09 & 1.15 & .06 & 1.23 & .05 \\
\hline Age & 73.04 & .32 & 73.29 & .23 & 73.2 & .19 \\
\hline Male & $.38^{*}$ & .02 & .45 & .02 & .42 & .01 \\
\hline Black & .02 & .01 & .04 & .01 & .03 & .01 \\
\hline Other minority & .02 & .01 & .02 & .01 & .02 & 0 \\
\hline Hispanic & $.02^{*}$ & .01 & .04 & .01 & .03 & .01 \\
\hline Unmarried & $.07^{*}$ & .01 & .11 & .01 & .09 & .01 \\
\hline Widowed & .26 & .02 & .22 & .01 & .23 & .01 \\
\hline Number of kids & 3.43 & .1 & 3.31 & .08 & 3.36 & .06 \\
\hline Income $/ 10,000$ & 5.34 & .38 & 6.27 & .38 & 5.93 & .28 \\
\hline Assets/10,000 & 40.09 & 4.37 & 51.01 & 4.67 & 46.99 & 3.37 \\
\hline Working & $.25^{*}$ & .02 & .2 & .01 & .22 & .01 \\
\hline $\begin{array}{l}\text { Mobility difficulty } \\
\text { index }\end{array}$ & $2.69^{* *}$ & .12 & 2.25 & .09 & 2.41 & .07 \\
\hline Number of close friends & $6.97^{* * *}$ & .45 & 5.37 & .2 & 5.96 & .21 \\
\hline Rely on friends & 3.1 & .04 & 3.03 & .03 & 3.06 & .03 \\
\hline Meet with friends & 3.18 & .05 & 3.2 & .04 & 3.19 & .03 \\
\hline $\begin{array}{l}\text { Number of close } \\
\text { family }^{3}\end{array}$ & 4.8 & .21 & 4.37 & .21 & 4.53 & .15 \\
\hline Rely on family ${ }^{3}$ & $3.13^{*}$ & .05 & 3 & .04 & 3.05 & .03 \\
\hline Meet with family ${ }^{3}$ & $2.56^{*}$ & .06 & 2.38 & .04 & 2.45 & .04 \\
\hline $\begin{array}{l}\text { Number of children } \\
\text { close with }\end{array}$ & $2.76^{* * *}$ & .08 & 2.4 & .06 & 2.53 & .05 \\
\hline Rely on children & $3.58^{* * *}$ & .04 & 3.38 & .04 & 3.45 & .03 \\
\hline Meet with children & $3.03^{*}$ & .05 & 2.87 & .04 & 2.93 & .03 \\
\hline Child living nearby & .59 & .02 & .54 & .02 & .56 & .01 \\
\hline
\end{tabular}

Note: Significance reported for t-tests between rural and nonrural means. ${ }^{1}$ CES-D = Center for Epidemiologic Studies Depression Scale. ${ }^{2}$ Number of difficulties in performing mobility, strength, and fine motor skills. ${ }^{3}$ Family $=$ any family member not living in the household. ${ }^{*} p<.05 .{ }^{* *} p<.01 .{ }^{* * *} p$ $<.001{ }^{* * * *} p<.0001$.

friendships, three different questions from HRS were used pertaining to: 1) the number of close friends; 2) the extent to which one can rely on friends; and 3) the frequency of meeting with friends. Specifically, the number of close friends variable asked respondents to indicate how many friends they would say they have a close relationship with. The extent to which one can rely on friends was assessed by asking respondents how much they can rely on their friends if a serious problem occurs $(1=a$ lot to $4=$ not at all). Responses were reverse-coded so that higher responses indicated greater confidence in friends. Last, the 
frequency of meeting with friends was evaluated through a single question that asked how often respondents met up with their friends. Responses were coded so that higher numbers indicated a greater frequency of meeting with friends $(1=$ only once or twice a year or never; 2 = every few months; $3=$ monthly; 4 = weekly). The same three questions were used to evaluate family relationships. The only difference was that, instead of friends, the questions asked about relationships with family members that were not residing in the same household with them at the time of the survey. The same questions were also used to examine relationships with children plus an additional question which asked whether or not the respondent had a child living nearby (i.e., within 10 miles). Responses were coded so that $1=$ child living nearby and $0=$ no child living nearby.

Physical well-being. In order to assess physical well-being, the mobility, strength, and fine motor skills measure available in the HRS was used. This measure asked participants about their abilities to perform 12 different activities (including things like walking a block, climbing stairs, stooping, picking up a dime, and others). The activities are more challenging than ADLs and having difficulties in these activities are thought of as precursors to limitations in ADLs (Fonda \& Herzog, 2004). Respondents were asked if difficulty was present in performing the given activity, and responses were coded using binary codes $(1=$ yes; $0=$ no $)$. After being coded, the responses were summed making the variable equal to the number of difficulties $(0-12)$ in mobility, strength, and fine motor skills. Research has indicated that this measure is a valid measure of physical functioning and has good internal consistency $(\alpha=.87$ ) (Fonda \& Herzog).

Other predictors. In addition to the variables above, several other predictor variables - age, gender, race, ethnicity, marital status, and socioeconomic status - were included in our analyses because previous research has indicated that they are related to levels of depression. Age was calculated by subtracting participants' years of birth from 2004, the year data was collected. Gender was included by coding male participants as 1 and female participants as 0 . For race, Black was coded as 1 if participants self-identified as Black, otherwise 0. Although there are several categories of race that participants may identify with in the HRS, there were too few participants in any single of these categories to be included in multivariate analyses. As a result, we collapsed those persons into an other minority category coded as 1 for participants who identified with a minority group other than Black, and otherwise coded as 0 . In terms of ethnicity, participants who identified as Hispanic were coded as 1 and all other participants were coded as 0 . In regard to marital status, participants who were divorced, separated, or nevermarried were coded as 1 for unmarried. Widowed participants were coded as 1 , otherwise 0 . The implied comparison category was married. Three indicators were used to measure socioeconomic status. Estimates of annual income and net worth were two of these indicators and are based on imputed HRS data. These data are calculated and imputed based on a large number of questions asked in the HRS survey. A third indicator of socioeconomic status, working, was binary and coded as 1 for participants who indicated that they were working at a full-time job and 0 for all other participants.

Approach. Given our first research question was to examine potential differences in depressive symptoms between rural and nonrural persons, the first step in data analyses was a simple t-test that examined whether or not the mean of depressive symptoms varied between rural and nonrural persons. Next, predictive models of depressive symptoms were developed to more fully examine our second and third research questions. To examine our second question, a linear regression model was used to predict depressive symptoms while controlling for other known predictors of depression that included age, gender, race, and socioeconomic status. An additional regression model was developed that added interaction terms to assess how rurality and social support were related to depressive symptoms. These variables were created by taking the product of rurality and each social support indicator.

\section{Results}

As can be seen in Table 1, rural participants experienced significantly more depressive symptoms $(\mathrm{M}=1.37)$ than their nonrural counterparts $(\mathrm{M}=1.23)$, although the difference was small $(\mathrm{t}=-2.09, p<.05)$. This result gave some, albeit weak, support for the hypothesis that rural persons experience more depressive symptoms than nonrural persons. It may be, however, that regardless of little difference in the number of depressive symptoms, the experience of those symptoms and the context in which those symptoms are coped with vary across rurality.

As expected of a sample of older persons, participants were more likely to be female than male, but rural participants were more likely to be female than nonrural participants $(\mathrm{t}=2.48, p$ $<.05)$. Rural participants were less likely than nonrural participants to be Hispanic $(\mathrm{t}=2.20, p<.05)$, less likely to be unmarried $(\mathrm{t}=2.20, p<.05)$, and more likely to be working $(\mathrm{t}=$ $-1.96, p<.05)$. In addition, rural participants, as compared to others, were more likely to experience limitations in mobility, strength and fine motor skills $(\mathrm{t}=-3.02, p<.01)$ and have more close friends $(t=6.97, p<.001)$. In spite of having more close friends, there was no difference in the perceived ability to rely on friends by rural status $(\mathrm{t}=-1.42, p=$ n.s. $)$.

There was no difference by rurality in the number of family members with whom participants had close relationships $(\mathrm{t}=$ $-1.37, p=$ n.s.), but rural participants were slightly more likely than others to perceive that they could rely on family members $(\mathrm{t}=-2.11, p<.05)$. Rural persons were more likely to meet with family members than their nonrural counterparts $(\mathrm{t}=$ $-2.51, p<.05$ ). Rural participants were substantively more likely than nonrural participants to have close relationships with adult children $(\mathrm{t}=-3.74, p<.001)$, perceive that they could rely on adult children $(\mathrm{t}=-3.62, p<.001)$, and meet with adult children $(\mathrm{t}=-2.35, p<.05)$. There was no difference by rurality in the likelihood of living close to at least one adult child $(\mathrm{t}$ $=-1.84, p=$ n.s.).

Two regression models were constructed. The first model included only sociodemographic variables and estimates of limitations in mobility, strength, and fine motor skills. As can be seen in Table 2, there was a small negative relationship between age and depressive symptoms, Black participants experienced more depressive symptoms than other participants, widowed participants experienced more depressive symptoms than married participants, and limitations in mobility, strength, and fine motor skills were positively related to depressive symptoms. None of the other variables included in the regression model were significant. As a whole, this model predicted 19 percent of the variance in depressive symptoms.

The second regression model included the same variables as 
Table 2.

Hierarchical regression predicting depression $(\mathrm{N}=1250)$.

\begin{tabular}{|c|c|c|c|c|}
\hline \multirow[b]{2}{*}{ Variable } & \multicolumn{2}{|c|}{ Model 1} & \multicolumn{2}{|c|}{ Model 2} \\
\hline & $B$ & $\beta$ & $B$ & $\beta$ \\
\hline \multicolumn{5}{|l|}{ Sociodemographic } \\
\hline Age & $-.02^{*}$ & -.07 & $-.02^{*}$ & -.06 \\
\hline Male & .18 & .05 & .08 & .02 \\
\hline Black & $.88^{* *}$ & .09 & $.94^{* * *}$ & .09 \\
\hline Other minority & .44 & .04 & .29 & .02 \\
\hline Hispanic & .24 & .02 & .08 & .01 \\
\hline Unmarried & .29 & .05 & .21 & .03 \\
\hline Widowed & $.61^{* * * *}$ & .14 & $.64^{* * * *}$ & .15 \\
\hline Number of children & .02 & .03 & $.06^{*}$ & .08 \\
\hline Income $/ 10,000$ & 0 & -.01 & 0 & 0 \\
\hline Assets/10,000 & 0 & -.02 & 0 & -.01 \\
\hline Working & $-.24^{*}$ & -.06 & $-.26^{*}$ & -.06 \\
\hline Mobility difficulty index ${ }^{1}$ & $.28^{* * * *}$ & .38 & $.23^{* * * *}$ & .31 \\
\hline Living in a rural area & .12 & .03 & 1.1 & .29 \\
\hline \multicolumn{5}{|l|}{ Informal social support } \\
\hline Number of close friends & - & - & -.01 & -.02 \\
\hline Rely on friends & - & - & $-.18^{*}$ & -.09 \\
\hline Meet with friends & - & - & $-.15^{*}$ & -.08 \\
\hline Number of close family ${ }^{2}$ & - & - & 0 & -.01 \\
\hline Rely on family ${ }^{2}$ & - & - & -.04 & -.02 \\
\hline Meet with family ${ }^{2}$ & - & - & .1 & .07 \\
\hline Number of close children & - & - & $-.11^{*}$ & -.1 \\
\hline Rely on children & - & - & .09 & .05 \\
\hline Meet with children & - & - & -.1 & -.07 \\
\hline Child living nearby & - & - & .02 & .01 \\
\hline \multicolumn{5}{|l|}{ Rural by social support variables } \\
\hline Rural x number of close friends & - & - & .01 & .04 \\
\hline Rural $\mathrm{x}$ rely on friends & - & - & -.1 & -.09 \\
\hline Rural $\mathrm{x}$ meet with friends & - & - & .03 & .03 \\
\hline Rural x number of close family & - & - & .01 & .02 \\
\hline Rural x rely on family & - & - & -.02 & -.02 \\
\hline Rural x meet with family & - & - & .02 & .02 \\
\hline Rural x number of close children & - & - & .03 & .03 \\
\hline Rural $x$ rely on children & - & - & $-.34^{*}$ & -.34 \\
\hline Rural $x$ meet with children & - & - & .03 & .03 \\
\hline Rural $x$ child living nearby & - & - & .02 & .01 \\
\hline Rural $x$ mobility difficulty index ${ }^{1}$ & - & - & $.08^{*}$ & .09 \\
\hline Intercept & 1.68 & 0 & 2.65 & 0 \\
\hline R-square & & & & \\
\hline
\end{tabular}

Note: Regression analyses were conducted using weighted data. ${ }^{1}$ Number of difficulties in performing mobility, strength, and fine motor skills. ${ }^{2}$ Family = any family member not living in the household. ${ }^{*} p<.05 .{ }^{* * *} p<.01 .{ }^{* * *} p<.001{ }^{* * * *} p<.0001$. 
included in the first. However, additional variables were added to examine how participants' social contexts were related to variation in depressive symptoms, as well as how those social contexts interacted with rurality.

In regard to relationships with friends, this study found that the number of friends with whom participants had close relationships was not related to depressive symptoms. However, the ability of participants to rely on friends and the frequency of meeting with friends were both related to lower levels of depressive symptoms. Relationships with family members were not significantly related to depressive symptoms with the single exception of the number of children with whom participants had close relationships.

Of the interactions with rurality, only two variables were significantly related to variation in depressive symptoms. First, rural participants who perceived that they could rely on adult children were likely to experience fewer depressive symptoms than nonrural participants who perceived that they could rely on adult children. Second, limitations in mobility, strength, and fine motor skills were related to higher levels of depressive symptoms for rural, as compared to nonrural, participants. As a whole, the additional variables in the second model increased the amount of variance explained in depressive symptoms to 24 percent.

\section{Disscussion}

The purpose of this study was to examine variation in depressive symptoms among older persons focusing on how that variation may be related to rurality and informal social support. Three central research questions were examined. Are there variations in depressive symptoms by rurality? Are variations in depressive symptoms related to informal social support? And are there interactions between rurality and informal social support in regard to predicting depressive symptoms?

Regarding the first research question, results from this study found a small, but significant difference in depressive symptoms by rurality. Although small, this significant difference is likely substantive to older persons themselves, as well as the rural communities that they live in. As noted by Callahan and colleagues (1997), depressive symptoms are related to a greater likelihood of the use of emergency departments, hospitaliztions, and diagnostic tests. These are likely to increase the strains placed on rural health agencies that are already constrained by rurality (Rogers, 2002b). There is also some evidence that, in rural areas, these risks may not be alleviated by mental health services.

Mental health services can be important resources as people cope with depressive symptoms in their lives. Again, however, this may place rural persons at increased risk in comparison to nonruralpersons. As noted by Rathbone McCuan and Bane (2003), there are significant barriers to accessing mental health services in rural areas. These included limited resources and geographic distance to services, as well as fear of stigmatization and negative attitudes toward mental health services. Although mental health services may be important resources to help older persons cope with depressive symptoms, this research suggests that there may be significant barriers for rural persons accessing those services. However, one limitation of this study is that there were no direct measures of the availability of mental health services or participants' attitudes toward those services, an indication that more research is needed.
Given those barriers, the focus of this study was on interpersonal relationships with friends and family members and how those relationships interacted with rurality to predict depressive symptoms. Again, this study found significant, but small, relationships between interpersonal relationships and rurality. These findings are not surprising and well established by previous studies. For example, Oxman, Berkman, Kasl, Freeman, and Barret (1992) found that functional disability and changes in social networks were the largest contributors to variance explained in depressive symptoms, even after controlling for baseline depression levels. In particular, this study found that children making weekly visits to participants were predictive of lower levels of depressive symptoms. It was not surprising that relationships with friends were related to lower levels of depressive symptoms.

Whereas few interactions with rurality were significant, the two significant variables are indicative of an important experience in the ecology of rural aging. Specifically, this study found that participants' perceptions that they could rely on their adult children to meet their needs was more salient in regard to reducing depressive symptoms for rural than nonrural participants. It is not clear why. However, it may be that rural persons are relying on the informal assistance of adult children to provide them with assistance that nonrural persons may be able to seek from formal health care providers.

This interpretation is complemented by the finding that increased limitations in mobility, strength, and fine motor skills were more influential in explaining depressive symptoms in rural than urban persons. Again, one interpretation of this finding is that barriers associated with accessing formal healthcare services for rural persons as compared to nonrural persons results in a disadvantage in regard to coping with physical health issues and limitations in functioning.

In the end, this study suggests that rural older persons may face barriers to accessing rural health services. Therefore, it is not surprising that depressive symptoms are exacerbated by physical limitations for rural persons as compared to others. It also follows that, in this context, the importance of being able to rely on adult children is more important to the psychological well-being of older rural, than nonrural, persons.

It is important to note several limitations of the study. First, the effect sizes reported in this study were significant, but small. Consequently, only 24 percent of the variance was explained in the full model. Nevertheless, even small differences can be substantive and this study does provide important evidence for guiding practice and future research.

A second limitation of this study is that the data do not allow for a direct examination of participants' access or lack of access to formal health care services. Instead, this is inferred based on previous studies of rural aging and health (Rathbone-McCuan $\&$ Bane, 2003). More research is needed to clearly explicate the hypothesized link between rurality, access to formal health care services, and depressive symptoms.

In spite of those limitations, this study does point to some important implications. First, this study suggests that intergenerational relationships are likely more salient for rural persons as compared to nonrural persons. That is, rural persons may be more likely to rely on adult children to meet their needs than nonrural persons. It is important, therefore, that health care providers and social workers develop an understanding of the availability and willingness of adult children to provide assistance to older persons. The quality of intergenerational rela- 
tionships, in general, have been found to be key for informal caregiving (Ganong \& Coleman, 1999; Killian \& Ganong, 2002), and this study suggests that those relationships may be more important for rural than nonrural persons.

\section{REFERENCES}

Bierman, A., Fazio, E. M., \& Milkie, M. A. (2006). A multifaceted approach to the mental health advantage of the married: Assessing how explanations vary by outcome measure and unmarried group. Journal of Family Issues, 27, 554-582. doi: 10.1177/0192513X05284111

Braam, A. W., Prince, M. J., Beekman, A. T. F., Delespaul, P., Dewey, M. E., Geerlings, S. W. et al. (2005). Physical health and depressive symptoms in older Europeans. British Journal of Psychiatry, 187, 35-42. doi:10.1192/bjp.187.1.35

Buckwalter, K. C., Davis, L. L., Wakefield, B. J., Kienzle, M. G., \& Murray, M. A. (2002). Telehealth for elders and their caregivers in rural communities. Family and Community Health, 25, 31-40. doi:10.1097/00003727-200210000-00007

Butler, M. A., \& Beale, C. L. (1994). Rural-urban continuum codes for metro and non-metro counties, 1993 (Staff Report No. 9425). Washington DC: US Department of Agriculture, Agriculture and Rural Economy Division, Economic Research Service.

Callahan, C., Kesterson, J., \& Tierney, W. (1997). Association of symptoms of depression with diagnostic test charges among older adults. Annals of Internal Medicine, 126, 426-433.

Clarke, P., Fisher, G., House, J., Smith, J., \& Weir, D. (2007). Guide to content of the HRS psychosocial leave-behind participant lifestyle questionnaires: 2004 \& 2006.

http://hrsonline.isr.umich.edu/docs/userg/HRS2006LBQscale.pdf

Djernes, J. K. (2006). Prevalence and predictors of depression in populations of elderly: A review. Acta Psychiatrica Scandinavica, 113, 372-387. doi:10.1111/j.1600-0447.2006.00770.x

Engedal, K. (1996). Mortality in the elderly-A 3-year follow-up of an elderly community sample. International Journal of Geriatric Psychiatry, 11, 467-471.

doi:10.1002/(SICI)1099-1166(199605)11:5<467::AID-GPS338>3.0. $\mathrm{CO} ; 2-\mathrm{S}$

Fonda, S., \& Herzog, A. R. (2004). Documentation of physical functioning measured in the Health and Retirement Study and Asset and Health Dynamics among the Oldest Old Study. http://hrsonline.isr.umich.edu/docs/userg/dr-008.pdf

Ganong, L. H., \& Coleman, M. (1999). Changing families, changing responsibilities: Family obligations following divorce and remarriage. Mahwah: Lawrence Erlbaum Associates.

Gatz, M., \& Smyer, M. A. (1992). The mental health system and older adults in the 1990s. American Psychologist, 47, 741-751. doi:10.1037/0003-066X.47.6.741

Himmelfarb, S. \& Murrell, S. A. (1983). Reliability and validity of five mental health scales in older persons. Journal of Gerontology, 38, 333-339. doi:10.1093/geronj/38.3.333

House, J. S., Landis, K. R., \& Umberson, D. (1988). Social relationships and health. Science, 241, 540-545.

doi:10.1126/science.3399889

Johnson, J. E. (1998). Stress, social support, and health in frontier elders. Journal of Gerontological Nursing, 24, 29-35.

Katon, W. J., Lin, E., Russo, J., \& Unutzer, J. (2003). Increased medical costs of a population-based sample of depressed elderly patients. Archives of General Psychiatry, 60, 897-903. doi:10.1001/archpsyc.60.9.897

Killian, T. S., \& Ganong, L. H. (2002). Ideology, context, and obligations to assist older persons. Journal of Marriage and the Family, 64, 1080-1088. doi:10.1111/j.1741-3737.2002.01080.x

Killian, T.S., Turner, J., \& Cain, R. (2005). Depressive symptoms of caregiving women in midlife: The role of physical health. Journal of Women \& Aging, 17, 115-127. doi:10.1300/J074v17n01_09

Kohout, F. J., Berkman, L. F., Evans, D. A., \& Cornoni-Huntley, J. (1993). Two shorter forms of the CES-D depression symptoms index. Journal of Aging and Health, 5, 179-193. doi: $10.1177 / 089826439300500202$

Langa, K. M., Valenstein, M. A., Fendrick, A. M., Kabeto, M. U., \& Vijan, S. (2004). Extent and cost of informal caregiving for older Americans with symptoms of depression. The American Journal of Psychiatry, 161, 857-863. doi:10.1176/appi.ajp.161.5.857

Montani, L, Billaud, N., Tyrrell, J., Fluchaire, I., Malterre, C., Lauvernay, N., Couturier, P., \& Franco, A. (1997). Psychological impact of a remote psychometric consultation with hospitalized elderly people. Journal of Telemedicine and Telecare, 3, 140-145. doi: $10.1258 / 1357633971931048$

Oxman, T. E., Berkman, L. F., Kasl, S., Freeman, D. H., \& Barret, J. (1992). Social support and depressive symptoms in the elderly. American Journal of Epidemiology, 135, 356-368.

Penninx, B. W. J. H., Guralnik, J. M., Ferrucci, L., Simonsick, E. M., Deeg, D. J. H., \& Wallace, R. B. (1998). Depressive symptoms and physical decline in community-dwelling older persons. The Journal of the American Medical Association, 279, 1720-1726. doi:10.1001/jama.279.21.1720

Probst, J. C., Laditka, S. B., Moore, C. G., Harun, N., Poweel, P., \& Baxley, E. G. (2006). Rural-urban differences in depression prevalence: Implications for family medicine. Family Medicine, 38, 653660.

Radloff, L. S. (1977). The CES-D scale: A self-report depression scale for research in the general population. Applied Psychological Measurement, 1, 385-401. doi:10.1177/014662167700100306

Rathbone-McCuan, E., \& Bane, S. (2003). Rural mental health: A discussion of service capacity building for rural elders. Journal of Gerontological Social Work, 41, 301-312. doi: $10.1300 / J 083 v 41 \mathrm{n} 03 \quad 07$

Ried, L., \& Planas, L. (2002). Aging, health, and depressive symptoms: Are women and men different? Journal of Women's Health, 11, 813824. doi:10.1089/15409990260430963

Rogers, C. C. (2002a). Rural health issues for the older population. Rural America, 17, 30-36.

Rogers, C. C. (2002b). The older population in 21 st century rural America. Rural America, 17, 1-10.

Schulz, R., \& Beach, S. R. (1999). Caregiving as a risk for mortality: The caregiver health effects study. Journal of the American Medical Association, 282, 2215-2219. doi:10.1001/jama.282.23.2215

Steffick, D. E. (2000). Documentation of affective functioning measures in the Health and Retirement Study. http://hrsonline.isr.umich.edu/docs/userg/dr-005.pdf

Sumner, C. R. (2001). Telepsychiatry: Challenges in rural aging. The Journal of Rural Health, 17, 370-373. doi:10.1111/j.1748-0361.2001.tb00291.x

Wilson, R., Mendes de Leon, C., Bennett, D., Bienias, J., \& Evans, D. (2004). Depressive symptoms and cognitive decline in a community population of older persons. Journal of Neurology, Neurosurgery and Psychiatry, 75, 126-129.

Yang, Y. (2006). How does functional disability affect depressive symptoms in late life? The role of perceived social support and psychological resources. Journal of Health and Social Behavior, 47, 355-372. doi:10.1177/002214650604700404

Yang, Y., \& George, L. K. (2005). Functional disability, disability transitions, and depressive symptoms in late life. Journal of Aging and Health, 17, 263-292. doi:10.1177/0898264305276295

Zunzunegui, M. V., Beland, F., Llacer, A., \& Leon, V. (1998). Gender differences in depressive symptoms among Spanish elderly. Social Psychiatry and Psychiatric Epidemiology, 33, 195-205. doi: $10.1007 / \mathrm{s} 001270050043$ 